\title{
KNOWLEDGE AND PRACTICE ON BIRTH PREPAREDNESS AND COMPLICATION READINESS AMONG PREGNANT WOMEN IN SELECTED WARD OF BIRATNAGER MUNICIPALITY, NEPAL
}

\section{Sabitra Subedi ${ }^{1}$}

\begin{abstract}
Birth preparedness and complication readiness is the process planning for normal birth and anticipating the action needed in case of an emergency. Promoting birth and emergency planning helps to improve preventive behavior, increase awareness of mothers about danger signs and improvement in care seeking behavior in the case of obstetric complication. A cross sectional descriptive quantitative community-based study was conducted to assess knowledge and practice on birth preparedness and complication readiness among 150 pregnant women of 24 weeks gestation and above in selected wards of Biratnagar with non- probability purposive sampling.

The findings of the study showed that $22.7 \%$ of the respondents had adequate knowledge on the birth preparedness and complication readiness and $19.8 \%$ of respondents had adequate practice. However, the only $9.3 \%$ of respondents were prepared for birth complications. Analysis using chi square test identified statistically significant association between knowledge and practice. The study found significant association of knowledge with gravida and weeks of gestation. It seemed there is significant association of practice level with occupation and weeks of gestation and weeks of gestation. The study identified inadequate knowledge and practices on birth preparedness and complication readiness. Thus, the government office, policy makers and partner that are working in maternal health should give due emphasis to preparation for birth and its complication and provide information and education to all pregnant women at community level.
\end{abstract}

1 Ms. Subedi is a Lecturer, Biratnagar Nursing Campus, Morang, TU. 
Keywords: Knowledge, Practice, Birth Preparedness And Complication Readiness, Pregnant Mothers

\section{INTRODUCTION}

Among different issues in health system, maternal mortality has a high rate. As expressed by World Health Organization (WHO) worldwide maternal mortality rate 210/100000 has become a significant challenge for safe maternal wellbeing (WHO 2011). Relatively maternal mortality rate is less in developed countries which is 16 , even so, this rate is fundamentally higher in developing countries (240) and the equivalent for South Asia is 220 (WHO 2012). Ongoing measurements shows that this rate is even intensely high accounting to be 170 death for each 100000 live births in Nepal (DoHS 2011/2012).

Developed countries Birth Preparedness and Complication Readiness (BP/CR) is a strategy to promote utilization of skilled maternal and neonatal care timely, based on the theory that preparing for childbirth and being ready for complications reduces delays in obtaining this care. Birth preparedness helps to ensure that women can reach professional delivery when labour begins. In addition, birth preparedness can help reduce the delay that occurs when women experience obstetric complication, such as recognizing the complication and deciding to seek care, reaching the facility where skill care is available and receiving care from qualified provider at the facility. Birth and emergency planning is important because of the unpredictability of obstetric complications. Promoting birth and emergency planning helps to improve preventive behaviour, increase awareness of mothers about danger signs and improvement in care seeking behaviour in the case of obstetric complication (McPherson et al. 2006).

It has been acknowledged that receiving care from a skilled provider is the single most important intervention in safe motherhood but often women are confronted with delays in seeking care (Moran et al. 2006). To reduce the risks associated with pregnancy and childbirth and address delays, three major strategies have been adopted in Nepal such as "promoting birth preparedness and complication readiness including awareness raising and improving the availability of funds, transport and blood supplies", "encouraging for institutional delivery" and "expansion of 24-hour emergency obstetric care services (basic and comprehensive) at public health facilities in every district" (Department of Health Service 2012). Improving knowledge of obstetric danger signs and promoting birth 
preparedness practices are strategies aimed at enhancing utilization of skilled care in low-income countries (Kabakyenga et al. 2011). Despite the fact that toward the finish of 2008-2009, the birth preparedness package (BPP) turned out in every one of the 75 regions of Nepal (MOHP 2012). It is necessary to evaluate the model of birth preparedness to get an effective and safe outcome. NDHS (2011) showed that only 36\% saved money for delivery, $5 \%$ bought a home delivery kit and $2 \%$ contacted a health worker, 56\% arranged for food and clothing, 3\% made arrangement for transportation and nearly one-third of women said they had not made any preparations at all for the birth of their child (MOHP et al. 2012). Both the percentage of delivery conducted by skill birth attendance and institutional delivery was 44\% births (DoHS 2011/2012). These figures show a very poor status of birth preparedness in Nepal in spite of the implementation of birth preparedness package by the government. Therefore, the principal objective of this research is to assess knowledge and practice of birth preparedness and complication readiness among pregnant women.

\section{METHODS}

A cross-sectional descriptive community based study was conducted to identify knowledge and practice on birth preparedness and complication readiness among pregnant women. The study was conducted among pregnant women of 24 weeks gestation and above who were residing in ward no. 1, 2, 4, 6, 10, and 11 of the Biratnagar sub-metropolitan municipality. The Wards were selected purposively. Sampling technique was non-probability purposive. Sample size was 150 pregnant women. The study was conducted between $20 / 11 / 2072$ and 30/1/2073. Prior to preceding the data collection work, the field researcher prepared a sketch map of each sampled wards in consultation with the local key persons such as FCHVs. Data collection was done by researcher herself using pre tested, structured interview schedule. For the ethical approval, research proposal was approved from the centre for research, office of rector. Approval for data collection was taken from concerned authority; DPHO of Biratnagar. Informed consent was obtained from each respondent to ensure the right of the subject before interviewing them.

Collected data were entered and analyzed by using Statistical Package for Social Science (SPSS) version 20. In descriptive analysis mean and standard deviation was computed and Chi square Test was used to identify association with accepted level of statistical significance 
set at $p$ value $<0.05$. Inter-quartile range was used to identify the level of knowledge. Birth preparedness was measured by five indicators: identification of delivery place, identification of transport, identification of blood donor, money saving, and antenatal care check-up.

\section{RESULTS AND DISSCUSSION}

Out of 150 pregnant women, finding revealed that less than half (48\%) of respondents were between ages $20-24$ years with the mean age of $23 \pm 3$. Likewise maximum $133(88.6 \%)$ of respondents were Hindu. Similarly, about $47(31.3 \%)$ of respondents had secondary school and majority $113(75.3 \%)$ of the respondents were home makers. More than half $86(57.3 \%$ ) of the pregnant women were primigravida, about $63(42 \%)$ had more than 2 pregnancies and $6(4 \%)$ of the respondents had history of stillbirth. Regarding to the week of gestation $56(37.3 \%)$ of respondents were between 30-35 week, 56 (36.7\%) of respondents were between 24-29 weeks and 39(26\%) of respondents were above 30 weeks respectively.

Thefindings of this study showedabouthalf74(49.3\%)ofrespondents had moderately adequate knowledge, 42 (28\%) of the respondents had inadequate knowledge and only34 (22.7\%) of the respondents had adequate knowledge on the birth preparedness and complication readiness. However, the study conducted by Devi (2011) found that 51\% had moderately adequate knowledge, $45 \%$ had inadequate knowledge and $4 \%$ had adequate knowledge. Similarly, the study conducted in Mangalore revealed that the majority (75\%) of the respondents had average knowledge, 13\% had good knowledge and, 12\% had poor knowledge (Banjara 2013). This could be the fact that the difference in study area, socio-cultural characteristics and implemented of related health program.

In regards to knowledge on components of BPCR, analysis of the present study showed that Most of the respondents (91.3\%) had knowledge on saving money, $82.7 \%$ of respondents had knowledge on prepare essential items for clean delivery, $78.7 \%$ of respondents had knowledge on identification of place of delivery, $51.3 \%$ of respondents had knowledge on being aware of danger signs \& the need to act immediately and of respondents had knowledge on identify mode of transportation, $48 \%$ of respondents had knowledge on identification of skill provider, $40.7 \%$ of respondents had knowledge on Identifying the nearest institution that has 24 hours functioning $34.7 \%$ of respondents had knowledge on arranging blood donor and only about one forth of respondents $(24.7 \%)$ had knowledge on 
designating the decision maker on her during the emergency. These results is higher those reported by Hiluf and Fantahun (2008) in Ethiopia and Nandan et al. (2009) in India. This reason might be the study was conducted in the center of city where the information and better access of health care services is available.

Table 1: Knowledge of respondents on birth preparedness and complication readiness $n=150$

\begin{tabular}{lcc}
\hline $\begin{array}{l}\text { Components of birth prepared and complication } \\
\text { readiness* }\end{array}$ & Frequency & Percent \\
\hline Save money & 137 & 91.3 \\
Identification of place of delivery & 118 & 78.7 \\
$\begin{array}{l}\text { Prepare essential items for clean delivery } \\
\text { Being aware of danger signs \& the need to act }\end{array}$ & 724 & 82.7 \\
immediately & 77 & 51.3 \\
Identify a mode of transportation & 77 & 51.3 \\
Identification of skill provider & 72 & 48 \\
Arranging emergency funds & 62 & 41.3 \\
Identifying the nearest institution that has24 hours & 61 & 40.7 \\
functioning EmOC services & 52 & 34.7 \\
Arranging blood donor & 37 & 24.7 \\
Designating decision maker on her & & \\
\hline
\end{tabular}

*Multiple responses

In this study, regarding the danger sign, $80.7 \%, 74 \%$ and $78 \%$ of respondents had mentioned vaginal bleeding as danger sign during pregnancy, labour and child birth respectively. It might be due to visibility, other sign have also serious consequence. Sixty two percent, 50\%, $44 \%, 42 \% 40.7 \%, 32.7 \%, 31.3 \%, 30.4 \%$ and $26.7 \%$ of respondents had mentioned severe headache, accelerated/reduced fetal movement, swelling of hands/leg/face, water breaks without labour pain, severe abdominal pain, loss of conscious high fever, Convulsion, and reported blurred vision as danger sign during pregnancy, respectively. Similarly, 61.3\% , 50\%, $44.7 \%, 42.7 \%, 36 \%$ and $34.7 \%$, of the respondents had knowledge on severe headache, labor lasting $>12$ hours Placenta not delivered 30 minutes after delivery, convulsion, loss of conscious and high fever, as danger signs during labor and childbirth, respectively. Likewise, 60\%, 59.3\%, $46 \%, 44 \%, 32.7 \%, 30 \%, 28 \%$ and $26.7 \%$ of the respondents mentioned 
malodorous vaginal discharge, severe headache /blurred vision, high fever, loss of conscious, swollen of hands/legs and severe lower abdominal pain as danger signs during post-partum period, respectively. The finding of this study is high in comparisons with the study done in other African countries (Hiluf \& Fantumn 2008, Mutiso et al. 2008, Pembe et al. 2009, Onayade et al. 2010, Njelita 2011 \& Urassa et al. 2012). It might be due to significant progress in information education communication and behavior change intervention for safe motherhood in Nepal. Regarding the practice, finding of the study shows that more than half $(50.7 \%)$ of the respondents had moderate practice, $40 \%$ had adequate practice and $9.3 \%$ had inadequate practice. Even though they had moderate knowledge they had low level of practice. It might be what people say may not necessarily be what they practice.

This study showed that $88 \%$ of the respondents had identified place of delivery. However, the different studies (Onayade et al. 2010, Karkee et al. 2013 \& Mukhopadhyay et al. 2013) found similar results that around 85.7 percent of the respondents had identified place of delivery and study done in New Delhi revealed that $81.1 \%$ (Acharya, Kaur, Prasuna \& Rasheed 2015). This might be because of the attraction towards monetary incentives for institutional deliveries in government health facilities. However, the study conducted by Moran et al. (2006), MOHP, New ERA \& ICF Interational Inc. (2012) and Hailu et al. (2011) found lesser result than this study which was $78.8 \%, 71 \%, 37 \%$ and $8 \%$ respectively. In this study $(38.7 \%)$ of respondents had identified skill birth attendance at birth. This finding was inconsistent with the other studies done in Nepal (Karkee et al. 2013), Tanzania (Urassa et al. 2012) . This might be knowledge was not always converted into actual behavior. 
Table 2: Knowledge of respondents on danger signs during pregnancy, labour and child birth and postpartum $(n=150)$

\begin{tabular}{|c|c|c|}
\hline $\begin{array}{l}\text { Danger signs during pregnancy, labour and } \\
\text { postpartum* }\end{array}$ & Frequency & Percentage \\
\hline \multicolumn{3}{|l|}{ Danger sign during pregnancy } \\
\hline Vaginal bleeding & 121 & 80.7 \\
\hline Severe headache & 93 & 62 \\
\hline Accelerated/reduced fetal movement & 75 & 50 \\
\hline Swollen of hands/leg face & 66 & 44 \\
\hline Water breaks without labour pain & 63 & 42 \\
\hline Severe abdominal & 61 & 40.7 \\
\hline Loss of consciousness & 49 & 32.7 \\
\hline High fever & 47 & 31.3 \\
\hline Convulsion & 46 & 30.7 \\
\hline Blurred vision & 40 & 26.7 \\
\hline \multicolumn{3}{|l|}{ Danger sign during labour } \\
\hline Vaginal bleeding. & 111 & 74 \\
\hline Severe headache & 92 & 61.3 \\
\hline Labor lasting $>12$ hours & 75 & 50 \\
\hline Placenta not delivered 30 minutes after delivery & 67 & 44.7 \\
\hline Convulsion & 64 & 42.7 \\
\hline Loss of consciousness & 54 & 36 \\
\hline High fever & 52 & 34.7 \\
\hline \multicolumn{3}{|l|}{ Danger sign during postnatal } \\
\hline Vaginal bleeding & 117 & 78 \\
\hline Severe headache & 90 & 60 \\
\hline Malodorous vaginal discharge & 89 & 59.3 \\
\hline Severe lower abdominal pain & 69 & 46 \\
\hline High fever & 66 & 44 \\
\hline Loss of conscious & 49 & 32.7 \\
\hline Blurred vision & 45 & 30 \\
\hline Swollen of hands/legs & 42 & 28 \\
\hline Convulsion & 40 & 26.7 \\
\hline
\end{tabular}

*Multiple responses 
Regarding the preparation of blood donor, in this study only $21.3 \%$ of respondents prepared blood donors. Nawal and Goli (2013), Karkee et al. (2013) and Onayade et al. (2010) found that the respondents were less prepared for blood donors. On the other hand Araya (2011) found better result as $20.7 \%$ of the pregnant mothers had prepared blood donors prior to delivery. This less preparation of blood donors before delivery might be due to the fact that most pregnant women do not want to anticipate undesirable events in pregnancy, delivery and after delivery, hence they make no plans for emergencies, hoping and believing that everything will be normal. Regarding the level of birth preparedness and complication readiness, this study shows majority $90.7 \%$ of respondents were not prepared, $9.3 \%$ of respondents were well prepared. This was inconsistent with the study conducted by Nawal and Goli (2013), Karkee et al. (2013)and kaphle, Neupane, Kuwar and Acharya (2015). This might be due to lack of selfdecision making power of Nepalese women regarding their health and also $36.6 \%$ respondents were gestational age 30-35 weeks. Thus, the women might feel that it is best to wait till they are in the later stages of pregnancy before they can start getting prepared for delivery.

There is association between knowledge and practice as $p$-value is less than 0.05 (OR 0.378 , CI $0.181-0.778$ ). It shows there is difference between knowledge and practice as respondent who were knowledgeable were not in practice. In this study, there seemed to be significant association with gravid and weeks of gestation. Regarding the gravid the odds of having the knowledge in second and more gravid were 36 times higher than first gravida (OR 0.36 CI 0.168-0.807). In a study done in Kaski reported women were about fifteen times more likely to be prepared in later pregnancies than first one ( $(\mathrm{p}<0.001$, crude OR15.0, 95\%CI 6.64-33.86). Similarly, in this study, in weeks of gestation the level of knowledge was increases with increases weeks of gestation (OR 0.35 CI. 140-0.923). It seemed significant relationship with occupation and weeks of gestation. Regarding the occupation the odds of having adequate practice is 32 times 
higher in others (private employee, government employee, business) than home maker (OR 0.32 CI 0.136 - 0.760). This might be due to the exposure to mass media and communication of working women in comparison to housewives.

Table 3: Practices of respondents on birth preparedness and complication readiness $n=150$

\begin{tabular}{lcc}
\hline Birth plan & Frequency & Percent \\
\hline Saving money for delivery & 134 & 89 \\
Identified place of delivery & 132 & 88 \\
Designated birth companion & 123 & 82 \\
Designated decision maker & 114 & 76 \\
Prepared essential item for delivery & 90 & 60 \\
Identified institution with 24 hr EmOC services & 78 & 52 \\
Focus antenatal check up & 72 & 48 \\
Arranged for means of transportation & 71 & 47.3 \\
identified skilled provider & 58 & 38.7 \\
Prepared blood donors & 32 & 21.3 \\
\hline
\end{tabular}

Similarly in weeks of gestation the practice increases with increases weeks of gestations there were more respondent in adequate practice with 30-35 and more than 35 weeks of gestation in comparison to 24 to 29 weeks of gestation (OR 0.62 CI 0.021-0.170). In study done in Ethiopia, there was a statistically significant association between gestational age and preparation for birth and its complication. Women with the gestational age range of 5-8 months are 0.53 times less likely to prepare for birth and its complication when compared with the mothers greater than 8 months of pregnancy $(\mathrm{OR}=0.53,95 \% \mathrm{CI}=0.29,0.98)$ (Araya 2011). 
62 KNOWLEDGE AND PRACTICE ON BIRTH PREPAREDNESS AND ...

Table 4: Association of level of knowledge with selected demographic variables

\begin{tabular}{|c|c|c|c|c|c|}
\hline \multirow{2}{*}{ Variable } & \multicolumn{2}{|c|}{ Level of knowledge } & \multirow{2}{*}{ OR } & \multirow{2}{*}{$95 \% \mathrm{CI}$} & \multirow{2}{*}{$P$-value } \\
\hline & Inadequate & Adequate & & & \\
\hline $\begin{array}{l}\text { Religion } \\
\text { Hindu } \\
\text { Others }\end{array}$ & $\begin{array}{c}36(24 \%) \\
6(4 \%)\end{array}$ & $\begin{array}{l}98(65.3 \%) \\
10(10.7 \%)\end{array}$ & 1.633 & $.544-4.818$ & .374 \\
\hline $\begin{array}{l}\text { Education } \\
\text { Illiterate } \\
\text { Literate }\end{array}$ & $\begin{array}{l}9(6 \%) \\
33(22 \%)\end{array}$ & $\begin{array}{c}12(8 \%) \\
96(64 \%)\end{array}$ & .458 & $.177-1.186$ & .108 \\
\hline $\begin{array}{l}\text { Occupation } \\
\text { Home maker } \\
\text { Others }\end{array}$ & $\begin{array}{c}35(23.3 \%) \\
74.7 \%)\end{array}$ & $\begin{array}{l}78(52 \%) \\
30(20 \%)\end{array}$ & .520 & $.208-1.297$ & .161 \\
\hline $\begin{array}{l}\text { Gravida } \\
1 \\
>2\end{array}$ & $\begin{array}{c}31(20.7 \%) \\
11(7.3 \%)\end{array}$ & $\begin{array}{l}55(36.7 \%) \\
53(35.3 \%)\end{array}$ & .368 & $.168-.807$ & $.013^{*}$ \\
\hline $\begin{array}{l}\text { Week of gestation } \\
24-29 \\
30-35 \\
>35\end{array}$ & $\begin{array}{c}23(15.3 \%) \\
11(7.3 \%) \\
8(5.3 \%)\end{array}$ & $\begin{array}{c}32(21.3 \%) \\
45(30 \%) \\
31(20.7 \%)\end{array}$ & .359 & $140-.923$ & $0.019 *$ \\
\hline
\end{tabular}

Table 5: Association of level practice with selected demographic variable

\begin{tabular}{|c|c|c|c|c|c|}
\hline \multirow[t]{2}{*}{ Variable } & \multicolumn{2}{|c|}{ Level of practice } & \multirow[t]{2}{*}{ OR } & \multirow[t]{2}{*}{$95 \% \mathrm{CI}$} & \multirow[t]{2}{*}{$P$-value } \\
\hline & Inadequate & Adequate & & & \\
\hline \multicolumn{6}{|l|}{ Religion } \\
\hline Hindu & 50 & 84 & 2.800 & $.960-8.171$ & .052 \\
\hline Others & 10 & 6 & & & \\
\hline \multicolumn{6}{|l|}{ Education } \\
\hline Illiterate & 12 & 9 & .444 & .174- & .084 \\
\hline Literate & 48 & 81 & & .1 .132 & \\
\hline \multicolumn{6}{|l|}{ Occupation } \\
\hline Home maker & 52 & 61 & .324 & $.136-.769$ & $.009 *$ \\
\hline Others & 8 & 29 & & & \\
\hline Gravida & & & & $.429-1.617$ & .590 \\
\hline 1 & 36 & 50 & .833 & & \\
\hline$>2$ & 24 & 40 & & & \\
\hline \multicolumn{6}{|c|}{ Week of gestation } \\
\hline $24-29$ & 41 & 14 & 062 & $.021-.179$ & $.000^{*}$ \\
\hline $30-35$ & 13 & 43 & & & \\
\hline$>35$ & 6 & 33 & & & \\
\hline
\end{tabular}

$* \mathrm{P}<0.05$. 
Table 6: Association between level of knowledge and level of practice

\begin{tabular}{|c|c|c|c|c|c|c|}
\hline & & \multicolumn{2}{|c|}{ Practice level } & \multirow[t]{2}{*}{ OR } & \multirow[t]{2}{*}{$95 \% \mathrm{CI}$} & \multirow{2}{*}{$\begin{array}{c}P \\
\text { Value } \\
\end{array}$} \\
\hline & & Inadequate & Adequate & & & \\
\hline \multirow[b]{2}{*}{$\begin{array}{l}\text { Knowledge } \\
\text { level }\end{array}$} & Inadequate & $24(16 \%)$ & $18(12 \%)$ & \multirow[b]{2}{*}{.378} & \multirow[b]{2}{*}{$\begin{array}{l}.181- \\
.778\end{array}$} & \multirow[b]{2}{*}{$.008 *$} \\
\hline & Adequate & $36(24 \%)$ & $72(48 \%)$ & & & \\
\hline
\end{tabular}

\section{CONCLUSION}

This study revealed that only a small number of pregnant mothers were knowledgeable and well prepared on birth and its complication. Women with more gravid and week of gestation were knowledgeable and prepared than primi-gravida and early week of gestation. Information, Education and Communication (IEC) on birth preparedness and complication readiness for primi-gravida are recommended for improving birth preparedness and consequently the effects of pregnancy related complications in early week of gestation. The stakeholders that are working in areas of maternal health should come up with new strategies to inform birth preparedness at individual and community level. Such strategies would assist pregnant mothers to identify danger signs during antenatal, labour and delivery and prepare for obstetric complication and therefore seek emergency obstetric care on time to minimize maternal and neonatal mortalities.

\section{REFERENCES}

Acharya, A.S., Kaur, R., Prasuna, J.G. \& Rasheed, N. (2015). Making pregnancy safer - birth preparedness and complication readiness study among antenatal women attendees of a primary health center, Delhi. Indian Journal of Community Med 40(2): 127-134. doi: 10.4103/0970-0218.153881, http://www.ncbi.nlm.nih.gov/pmc/ articles/PMC4389500/.

Araya, L. (2011). Assessment of knowledge and practice on birth preparedness and complication readiness among antenatal clients in selected health centers in Addis Ababa, Ethiopia. Unpublished Bachelor's thesis report, School of Graduate Studies of Addis 
Ababa University, Ethiopia. http://etd.aau.edu.et/dspace/bitstream/ 123456789/2264/1/ 13318021228683830238539886931761978799 7 (Accessed: 19.11.2013).

Banjara, L.N. (2013). Assessment of knowledge on birth preparedness among primigravida women attending antenatal clinics of selected hospitals in Mangalore. Unpublished Master's Research Paper, Master of Science in Obstetrics and Gynaecological Nursing, Rajiv Gandhi University of Health Sciences, Karnataka, Bangalore http://14.139.159.4:8080/jspui/bitstream/123456789/9022/1/ Lavanya\%20N\%20Bangera\%20-\%20OBG.pdf (Accessed: 15.02 . 2014).

Department of Health survey, (2012). Annual report of department of health services (2011/2012). Ministry of Health and Population, Government of Nepal, Kathmandu. http://dohs.gov.np/?q=node/70.

Devi, M.K. (2011). Knowledge of antenatal mothers preparing for safe delivery. Nightingale Nursing Times, 7(3): 37-39.

Hailu, M., Gebremariam, A., Alemseged, F. \& Deribe, K. (2011). Birth preparedness and complication readiness among pregnant women in southern Ethiopia. PLOS ONE 6, doi: 10.1371/journal. pone. 002143 .

Hiluf, M. \& Fantahun, M. (2008). Birth preparedness and complication readiness among women in Adigrat town, north Ethiopia. Ethiopian Journal Health Development 22(1) doi:10.4314/ejhd.v22i1.10057

Kabakyenga, J. K., Östergren, P. O. Turyakira, E. \& Pettersson, K. O. (2011). Knowledge of obstetric danger signs and birth preparedness practices among women in rural Uganda. Reproductive Health 8(33). doi: 10.1186/1742-4755-8-33

Kaphle, H.P., Neupane, N., Kunwar, L.B. \& Acharya, A. (2015). Birth preparedness and complications readiness among women in Lekhnath Municiaplity, Nepal. Global Journal of Medicine and Public Health 4(3). http://www.gjmedph.org/uploads/O1-Vo4No3. pdf 
Karkee, R., Lee, A. H. \& Binns, C. W. (2013). Birth preparedness and skilled attendance at birth in Nepal: Implications for achieving millennium development goal 5. Journal of Midwifery 29(10): 1206-1210. doi: 10.1016/j.midw.2013.05.002.

McPherson, R.A., Khadka, N., Moore,J. M. \& Sharma, M. (2006). Are birth-preparedness programmes effective? Results from a field trial in Siraha district, Nepal. Journal of health, population and nutrition 24(4): 479-88.

MoHP., New ERA. \& ICF. (2012). Nepal demographic and health survey 2011. Ministry of Health and Population (MOHP), New ERA Kathmandu, Nepal, \& ICF International Inc. Calverton, Maryland.

Mukhopadhyay, D.K., Mukhopadhyay, S., Bhattacharjee, S., Nayak, S., Biswas, A. K. \& Biswas, A. B. (2013). Status of birth preparedness and complication readiness in Uttar Dinajpur District, West Bengal. Indian J Public Health 57(3): 147-53 http://www.ijph.in/article. asp?2013/57/147/119827 (Accessed: 27.02.2014).

Nandan, D., Kushwah ,S.S. \&. Dubey D.K. (2009). A study for assessing birth preparedness and complication readiness intervention in Rewa district of Madhya Pradesh: Department of Community Medicine, S.S. Medical College, Rewa, M.P. http://www.nihfw. org/pdf/RAHI-II\%20Reports/REWA.pdf (Accessed: 16.12.2013).

Nawal, D. \& Goli, S. (2013). Birth preparedness and its effect on place of delivery and post-natal check-ups. PLoS One, 8(5), doi: 10.1371/ journal.

Onayade, A.A., Akanbi, O.O, Okunola, H.A., Oyeniyi, C.F., Togun, O.O. $\&$ Sule, S.S. (2010). Birth preparedness and emergency readiness plans of antenatal clinic attendees in Ile-ife, Nigeria. The Nigerian postgraduate medical journal 17(1): 30-39. http://www.ncbi.nlm. nih.gov/pubmed/20348980 (Accessed: 24.02.2014)

Urassa, D. P., Pembe, A. B. \& Mganga, F. (2012). Birth preparedness and complication readiness among women in Mpwapwa district, Tanzania. Tanzania Journal of Health Research 14(1), doi: http:// dx.doi.org/10.4314/thrb.v14i1.8 
66 KNOWLEDGE AND PRACTICE ON BIRTH PREPAREDNESS AND ...

WHO, (2011). Global health observatory data repository. World Health Organization. http://www.who.int/gho/mortality_burden_disease/ en/ (Accessed: 12.01.2014)

WHO, (2012). Trends in maternal mortality: 1990 to 2010, WHO, UNICEF, UNFPA and The World Bank estimates. http://www. unfpa.org/ webdav/site/global/shared/documents/publications/2012/Trends in maternal mortality A4-1.pdf. (Accessed: 09.02.2014). 